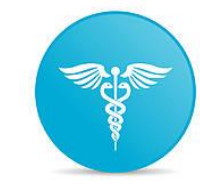

International Journal of Advances in Pharmacy and Biotechnology

Vol.4, Issue-2, 2018, 25-29

ISSN: $2454-8375$

Research Article

I J A P B Open Access

\title{
IN-VITRO ANTI BACTERIAL AND ANTHELMINTIC ACTIVITY OF TERMINALIA CHEBULA, MORINGA OLEIFERA AND ALLIUM SATIVUM
}

\author{
T. Kalpana*1, M. Madhavi', P. Mounika Rani ${ }^{3}$, R. Kavitha' ${ }^{3}$, M. Manisha3 ${ }^{3}$ K. Kalyani ${ }^{3}$ \\ ${ }^{1}$ Department of Pharmacognosy, Avanthi Institute of Pharmaceutical Sciences, Vizianagaram, India \\ 2Department of Pharmacology, Avanthi Institute of Pharmaceutical Sciences, Vizianagaram, India \\ ${ }^{3}$ Final year UG students, Avanthi institute of Pharmaceutical Sciences, Vizianagaram, India \\ *Corresponding author e-mail: koppula_k@yahoo.com \\ Received: 18 August 2018 Revised: 24 August $2018 \quad$ Accepted: 29 August 2018

\begin{abstract}
The objective of the current research work is to investigate the in-vitro anti- bacterial and anthelmintic activity.The combined tri-herbal methanolic extract made up of equal quantities of leaves of Moringa oleifera, seeds of Terminalia chebula, and fresh bulbs of Allium sativum was evaluated for its in-vitro antibacterial and anthelmintic activity and was compared with its individual methanolic extracts of Terminalia chebula. The anti-bacterial activity was evaluated against gram neagative and gram positive bacteria. Streptomycin was used as a standard drug. The Anthelmintic activity was evaluated against Pheretima posthuma. Albendazole was used as a standard drug. The experimental results showed that triherbal methanolic plant extracts possess better activity on both microorganisms and earthworms. The combined activity of Moringa oleifera, Terminalia chebula and Allium sativum has been reported for the
\end{abstract} \\ first time.
}

KEYWORDS: IN-vitro, Anthelmintic, Microorganisms, Streptococcus, Bacillus, Pseudomonas

\section{INTRODUCTION}

The use of natural medicines for treatment or prevention of bacterial infections or disorders is safe for maintenance of good health. There are so many inventions and research works done on natural drugs due to their high activity and less side effects ${ }^{1}$. Allium sativum commonly known as garlic which belongs to the family Liliaceae. Its biological activities are mainly related to heart and blood systems like blood pressure, heart attack and atherosclerosis. Louis paster was the first scientist who discovered the anti- bacterial activity of garlic on both gram positive and gram negative bacteria. Garlic has strong anti- bacterial activity ${ }^{2}$. Terminalia chebula commonly known as myrobalan which belongs to the family combretaceae. It shows its inhibitory activity against Helicobacter pylori, Xanthomonas campestri spv. Citri and salmonella typhi. It is used in ayurvedic formulation triphala as main ingredient which is used for kidney and liver dysfunctions ${ }^{3}$.

Moringa oleifera commonly known as moringa belongs to the family Moringaceae. It has anti- bacterial activity against E.coli, Pseudomonas aeruginosa, Staphylococcus aureus, Bacillus subtilis and Streptococcus. Other biological activities are anti- oxidant, 
anti- fungal, anti- inflammatory, anti- tumor and anti- ulcer. Now a days helminth infections are most common and spread widely throughout the world. Anthelminthic drugs are used for treatment of parasitic diseases. Over usage of these drugs may induce toxicity in humans. In order to overcome of these side effects natural medicines have been discovered.

\section{MATERIALS AND METHODS}

\section{Collection of plant:}

The fresh leaves of Moringa oleifera were collected near our house located in Visakhapatnam district and the seeds of Terminalia chebula and fresh bulbs of Allium sativum were purchased from the local market in Visakhapatnam.

\section{Preparation of plant materials:}

Fresh leaves of Moringa oleifera were collected, washed thoroughly and dried under shade and then made into fine powder using dry grinder. The seeds of Terminalia chebula were collected and dried under shade and then made into moderate powder. Fresh bulbs of Allium sativum were collected and the cloves are separated, peeled and washed and then dried under shade and were crushed using mortar and pestle. They were kept aside for two to three days crumbled with a blender to a fine powder and kept for further analysis.

\section{Extraction process:}

The extracts were taken in three separate round bottomed flask in equal ratio to this methanol is added and they were subjected to maceration process for two to three days followed by soxhelation. Then hydro distillation was carried out which is responsible for recollection of methanol. The extracts were stored in sample bottles in a refrigerator for further studies.

\section{IN- VITRO ANTI-BACTERIAL ACTIVITY}

Agar diffusion method is applied for screening of anti-bacterial activity.

\section{Strains for anti- bacterial activity:}

Pseudomonas aeruginosa, Bacillus subtilis, Streptococcus aureus

\section{Culture media:}

Culture media was procured by our college. Media was prepared using specified quantities of antibiotic assay medium and were thereafter sterilized by autoclaving at $15 \mathrm{lb}$ pressure at $121^{\circ} \mathrm{C}$ for $20 \mathrm{~min}$.

\section{Media for bacterial growth:}

Nutrient agar medium $4 \mathrm{~g}$ of agar powder, $1.5 \mathrm{~g}$ of pectin, $1.5 \mathrm{~g}$ of bees wax, $0.5 \mathrm{~g}$ of sodium chloride in $250 \mathrm{ml}$ distilled water. This solution is autoclaved at $121^{\circ} \mathrm{c} 15 \mathrm{lb}$ pressure for $20 \mathrm{~min}$.

\section{Agar disk diffusion method:}

Agar disk diffusion method is widely used to evaluate anti- bacterial activity of plants or microbial activity. Agar plates were prepared and test microorganisms are inoculated. The tri-herbal plant extracts were prepared in various concentrations $(50,100,150 \mu \mathrm{g} / \mathrm{ml})$. The individual plant extract concentrations were prepared in various concentrations $(100,200 \mu \mathrm{g} / \mathrm{ml})$. Streptomycin was taken as standard drug. The standard drug was prepared in concentrations of $10 \mu \mathrm{g} / \mathrm{ml}$. 
Filtered paper discs of $6 \mathrm{~mm}$ in diameter were soaked in extracts of different concentration and placed on the surface of agar plates. The agar plates are incubated at $34^{\circ} \mathrm{c}$ for 24 hours. After 24hours agar plates are examined and diameter of zone of inhibition is measured.

\section{IN- VITRO ANTHELMINTIC ACTIVITY}

\section{Earthworm collection:}

Indian adult earth worms (Pheretima posthuma) were collected from moist soil and washed thoroughly with water in order to remove the unwanted matter.

\section{In-vitro anthelmintic activity:}

The in-vitro anthelmintic activity of plant extracts were evaluated against Pheretima posthuma. All the drug extracts were prepared and kept aside before starting the experiment. Various concentrations of triherbal and individual (100, 80, 60, $40,20 \mathrm{mg} / \mathrm{ml}$ ) of extracts are prepared and tested against earthworms to determine the time of paralysis and death. Albendazole was taken as reference drug. The various concentrations of reference drug are taken as $20,40 \mathrm{mg} / \mathrm{ml}$. The earthworms are placed in Petri dishes containing different concentrations of methanolic extracts (combined form and individual form) and reference drug preparation and observed for time taken to cause paralysis and death. The time taken for paralysis is noted down if there is no movement for a period of time then it is regarded as death followed by fading of body colors.

\section{RESULTS AND DISCUSSION:}

In-vitro anti- bacterial activity:

In this study the tri herbal methanolic extract own anti- bacterial effect against streptococcus auereus and pseudomonas and the sensitivity of the bacterial gradually increased with increasing of concentration. Methanolic extract of Terminalia chebula own potent anti- bacterial activity against Pseudomonas aeruginosa, Bacillus subtilis and Streptococcus aereus (Table 1). All the results were compared to that of the reference drug (Table 1).

\section{In-vitro anthelmintic activity:}

The data revealed that tri- herbal methanolic extract showed better anthelmintic activity against earthworms. The results were comparable with that of the reference drug. By increasing the concentration of the extracts it procured better activity against earthworms. Methanolic extract of Terminalia chebula procured affective anthelmintic activity against earthworms (Table 2).

\section{CONCLUSION:}

On the basis of the above results it can be concluded that tri herbal methanolic plant extract a combination of three plants exerts eloquent anti- bacterial and anthelmintic activity because of the presence of the active biological principles.

\section{REFERENCES:}

1. Elham Abdelbasit Suleima and Wafa ballal Abdallah. In vitro activity of garlic (Allium sativa) on some pathogenic fungi. Europ journal of medicinal plants. 2014; 4(10): 1240-1250. 
2. Atheer abdulhameed khashan. Antibacterial activity of extract (allium sativum) against staphylococcus aureus in-vitro. Global journal of bio-science and biotechnology. 2014; 3(4): 346-348

3. Anwesa bag, Subir Kumar Bhattacharyya, Premananda Bharati Nishith kumar Pal and Rabi Ranjan Chattopadhyay. Evalution of antibacterial properties of chebulic myrobalan (fruit of terminalia chebula Retz) extracts against methicillin resistant Staphylococcus aureus and trimethoprim - sulpha methoxazole resistant uropathogenic Escherichia coli. African journal of plant science. 2009; 3 (2), 025-029.
4. S.Kalpana, S.Moorthi and Sushila kumari. Antimicrobial activity of different extracts of leaf of moringa oleifera (Lam) against gram positive and gram negative bacteria. International journal of current microbiology and applied sciences. 2013; 2(12): 514-518.

5. T. Kalpana, N. Nandini, R. Sai Priyanka, U. Sravya, Y. Likitha and P. Mounika. Phytochemical screening and anthelmintic activity of aerial parts of aqueous methanolic extract of euphorbia hirta against earth worms. International journal of Innovative research in science, engineering and technology. 2018;7(2):1323-1325.

Table 1: Anti-bacterial activity of the methanolic extract in-vitro

\begin{tabular}{|c|c|c|c|c|}
\hline \multirow{2}{*}{ Drug } & $\begin{array}{c}\text { Concentrations } \\
(\mu \mathrm{g} / \mathrm{ml})\end{array}$ & $\begin{array}{c}\text { Streptococcus } \\
(\mathrm{mm})\end{array}$ & $\begin{array}{c}\text { Pseudomonas } \\
(\mathrm{mm})\end{array}$ & $\begin{array}{c}\text { Bascillus } \\
(\mathrm{mm})\end{array}$ \\
\hline \multirow{2}{*}{ Terminalia chebula } & 100 & 30 & 26 & 28 \\
\cline { 2 - 5 } & 200 & 40 & 36 & 32 \\
\hline \multirow{2}{*}{ Tri- herbal extract } & 50 & 12 & 12 & 16 \\
\cline { 2 - 5 } & 100 & 20 & 20 & 28 \\
\cline { 2 - 5 } & 150 & 24 & 22 & 20 \\
\hline Standard & 10 & 17 & 12 & 11 \\
\hline
\end{tabular}


Table 2: Anthelmintic activity of methanolic extracts:

\begin{tabular}{|c|c|c|c|}
\hline \multirow{4}{*}{ Drug } & $\begin{array}{c}\text { Concentrations } \\
(\mu \mathrm{g} / \mathrm{ml})\end{array}$ & $\begin{array}{c}\text { Paralysis } \\
(\mathrm{min})\end{array}$ & $\begin{array}{c}\text { Death } \\
(\mathrm{min})\end{array}$ \\
\hline \multirow{4}{*}{ Terminalia chebula } & 100 & 40.54 & 50.08 \\
\cline { 2 - 4 } & 80 & 30.44 & 60.34 \\
\cline { 2 - 4 } & 60 & 40.47 & 65.23 \\
\cline { 2 - 4 } & 40 & 50.23 & 74.45 \\
\hline \multirow{5}{*}{ Tri- herbal extract } & 20 & 65.33 & 85.10 \\
\cline { 2 - 4 } & 100 & 10.23 & 15.56 \\
\cline { 2 - 4 } & 80 & 20.36 & 25.35 \\
\cline { 2 - 4 } & 60 & 25.47 & 35.06 \\
\cline { 2 - 4 } & 40 & 40.38 & 63.15 \\
\hline \multirow{5}{*}{ Standard } & 20 & 45.12 & 58.08 \\
\hline & 20 & 25.15 & 50.26 \\
\cline { 2 - 4 } & 40 & 23.50 & \\
\hline
\end{tabular}

\section{How to cite this article:}

Kalpana et al., In-vitro anti bacterial and anthelmintic activity of terminalia chebula, moringa oleifera and allium sativum. Int. J. Adv. Pharm. Biotech., 2018; 4(2): 25-29. 